\title{
IDENTITY AND CULTURE:
}

\section{A CULTURAL INTERPRETATION OF THE HOPI-NAVAJO LAND DISPUTE}

\section{IDENTIDAD Y CULTURA: \\ UNA INTERPRETACIÓN CULTURAL DE LOS NAVAJO-HOPI TIERRA DE CONTROVERSIAS}

\section{AUTOR/ES}

Otto F. von Feigenblatt: Profesor de la Nova Southeastern University. Florida (USA) journalalternative@hotmail.com

\begin{abstract}
This interpretive essay provides a socio-cultural explanation of the Navajo-Hopi Land Dispute based on the rich narrative account of the conflict by Benedek (1999). A macrolevel of analysis is taken so as to identify the general trends of the conflict. SPITCEROW, the acronym for a simple analytical instrument, is used to identify the main components of the overall conflict. Finally an analytical section explains the conflict through the use of the Social Identity Theory and supports it by using a broad cultural approach. The paper concludes that identity needs were at the core of the conflict and that once those issues were addressed and satisfactorily resolved, secondary issues were amicably negotiated and a settlement was reached.
\end{abstract}

\section{KEY WORDS}

Ethnic Conflict - Identity Politics - Land Dispute - Conflict Analysis

\section{RESUMEN}

Este ensayo de carácter interpretativo propone una explicación socio-cultural sobre la disputa territorial Navajo-Hopi, basándose en la rica narrativa escrita sobre el conflicto por Benedek (1999). Un macronivel de análisis es utilizado para identificar las tendencias generales del conflicto. SPITCEROW, el acrónimo para un instrumento analítico simple, es utilizado para identificar los componentes principales del conflicto en su impresión general o global. Finalmente, una sección analítica explica el conflicto a través del uso de la Teoría de la Identidad Social y la apoya utilizando una amplia aproximación cultural. El documento concluye que las necesidades de identidad se encontraban en el núcleo del conflicto y que una vez que esas cuestiones fueron abordadas y resueltas de manera satisfactoria, las cuestiones secundarias fueron negociadas de manera amigable y se llegó 


\section{PALABRAS CLAVE}

Conflicto étnico - Identidad política - Disputa territorial - Análisis del Conflicto

\section{ÍNDICE}

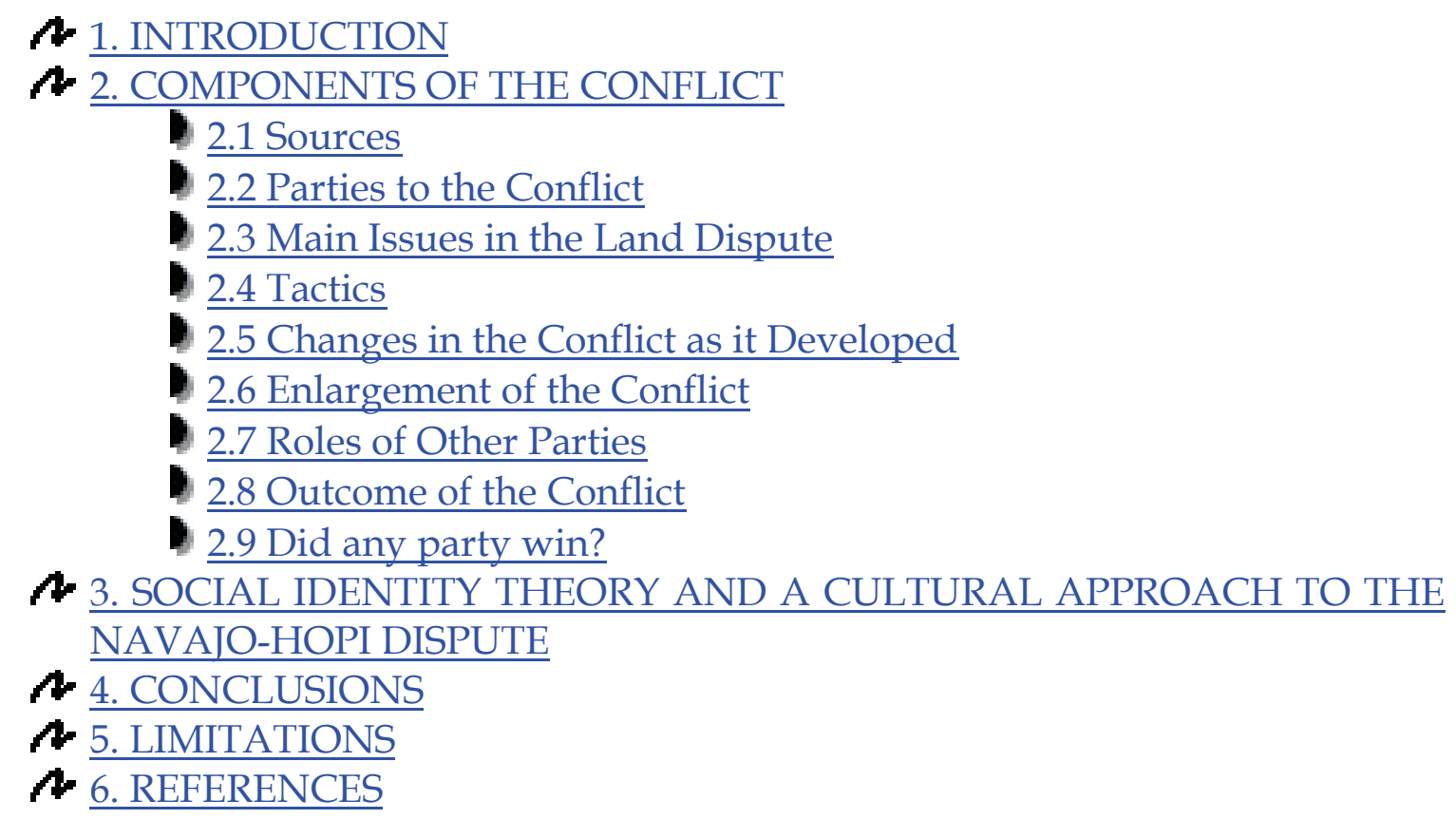

\section{INTRODUCTION}

The Navajo-Hopi Land Dispute is a complex conflict that involves: culture, the legal system, identity, communication problems, resource scarcity, and many other factors. However, this paper will concentrate on two main factors: culture and identity. By focusing on those two factors, it is possible to understand the dispute from the point of view of the tribes themselves. This approach was chosen taking into consideration that the two tribes are not part of mainstream American society and that on repeated occasions they have stressed the importance of protecting their distinct cultures (Benedek 1999, p. 356).

Two Native American tribes in the State of Arizona have been involved in a more than one hundred years old dispute over land use and property rights. The Hopis, a Pueblo people, with a sedentary history have the oldest claim to the land while the Navajo, a relatively recent arrival to the region, makes competing claims based on need as well as practice. This very old and sometimes bitter dispute has involved other actors such as the State of Arizona and even the Federal Government and thus gained national and international visibility for the conflict. A simple way to summarize the conflict would be to say that the Hopis were there first and then the Navajo arrived from the 
North due to pressure from the Federal Government. The Hopis allowed the Navajos to live in the land near the mesas were the Hopi villages were, and still are, located. Reductions in the size of the reservation and population growth in the Navajo population, has led to more Navajos moving near the Hopi villages. A complex web of Federal rulings have made property rights over the land more complicated by the granting legal title to some land to the Navajos while also granting title to some land to the Hopis. The result was that the small Hopis reservation was engulfed by the larger Navajo reservation. The following sections explain the legal battles in more detail as well as the cultural differences between the Hopis and the Navajos.

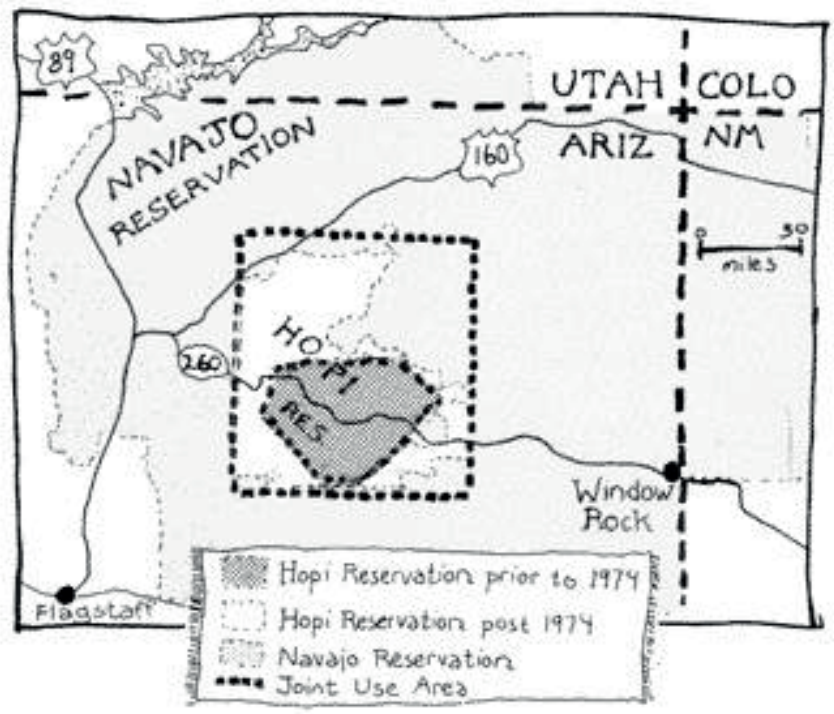

Fig. 1. Navajo and Hopi Reservations (Gilles 1997)

The first part of the paper will describe the main components of the dispute by using the instrument called "SPITCEROW", which stands for: sources, parties, issues, tactics, changes, enlargement, roles, outcomes, and winner. Thus, the instrument will help organize all of the information provided by Benedek in narrative form, and prepare the way for a cultural interpretation of the overall conflict.

Finally, the overall conflict will be interpreted through a cultural and identity approach emphasizing the general trends of the dispute. Since this paper takes the view that the land dispute started since the Navajos moved to the area, around 150 years ago, the paper will concentrate on the macro-level of the conflict and avoid unnecessary details such as a detailed description of the legal history of the dispute and the bureaucratic struggles related to the Relocation Commission.

\section{COMPONENTS OF THE CONFLICT}




\subsection{SOURCES}

The Navajo-Hopi Land Dispute can be traced back to the arrival of the Navajos to the region inhabited by the Pueblos. Around 150 years ago the Navajos moved to the region of Arizona and New Mexico and settled near the Hopis, a Pueblo people (Benedek 1999, p. 41). The Navajos originally came as raiders and did not settle permanently. However, after a few years they started to settle in the lands near the Hopi Mesas. According to Hopi legend, the leaders of the Navajo asked them for permission to settle in those lands and the Hopis agreed to let them stay as long as they would follow Hopi laws, during that agreement the Navajo representatives gave the Hopis dolls as gifts which represented the power to harm the Navajos (Benedek 1999). The Hopis still keep those dolls as proof of the encounter. On the other hand, the Navajos believe that that Land was given to them by the Great Spirits for them to take care of it, after they arrived from their long journey.

The Hopis are a village people and they value the law. Thus they were greatly offended by the Navajo practice of raiding and stealing (Benedek 1999, p. 43). This means that the relationship between the two tribes was plagued by conflict since the beginning. Nevertheless, the two tribes were able to coexist relatively peacefully during colonial times settling their disputes on a case by case basis. At the end of the Mexican-American War, the Treaty of Guadalupe Hidalgo was signed between Mexico and the United States. The treaty ceded the lands that included the Hopis and the Navajos to the United States but included a provision guaranteeing the independence of both tribes (Benedek 1999, p. 115). Needless to say, the United States did not respect the treaty and greatly undermined the trust of the Indians for the United States government.

In 1882 an Indian Agent of the Federal Government, J.H. Fleming, convinced the government to draw a rectangular line around the Hopi mesas and to declare it a reservation for the Hopis (Benedek 1999, p. 35). This area of land is called the 1882 Executive Order Area and included many Navajo families (Benedek 1999, p. 23). The reservation was then expanded to include the Navajos in 1934, which meant that the Hopi Reservation was completely surrounded by the Navajo Reservation. Consequently, in 1934 the Indian Reorganization Act instructed tribes for form a government and to draw constitutions (Benedek 1999, p. 36). Those laws artificially divided the land for the first time and introduced a foreign idea to the tribes, secular government (Hocker 2007, p. 75). The division of land was a private matter before that point, it was constantly negotiated between individual Hopis and Navajos, but when the government stepped in to divide the land on paper, it created a precedent and set the roots for the conflict.

Many laws were passed assigning one part of the land to one side or the other and a Representative in Congress, called Morris Udall introduced a bill to allow the tribes to sue each other to determine ownership of the land, Public Law 85-547 (Benedek 1999, p. 36). Finally, in 1958 the Hopis sued the Navajos in the case called Healing vs. Jones 
(Benedek 1999, p. 36). That was the beginning of the prolonged legal battle that would lead to the relocation of thousands of Navajos.

Taking into consideration that this paper takes a macro-level view of the land dispute, the most important sources of the conflict are: the differences in lifestyles between the Hopis and Navajos (village-dwellers vs semi-nomadic sheep herders), the value differences between the two tribes (law abiding vs opportunistic), and the influence of external forces such as the US government in trying to impose mainstream values regarding property rights to the dispute. It should be noted that while those are the most important sources of the conflict there are many secondary sources to the subconflicts that arose due to the tactics employed by both parties and by external forces, but they are not discussed here due to space constraints and due to the macro-level of analysis of the paper.

\subsection{PARTIES TO THE CONFLICT}

The two main parties to the conflict are the Hopis and the Navajos. The Hopis can be described as generally law-abiding, village-dwellers. They have inhabited the mesas for almost one thousand years and have an elaborate religious hierarchy (Benedek 1999, p. 45). Hopis tend to avoid direct confrontation and instead show disagreement by avoidance and silence. As a small tribe, of about 10,000 members, they are greatly outnumbered by the Navajos, who are the largest tribe in the country (Benedek 1999, p. 25). There are 14 Hopi villages that are located on top of mesas. Hopis mostly do farming and handicrafts while some have gotten involved in cattle ranching.

Hopis can be divided into three main groups. A small group of highly political Hopis who are involved in the tribal government at one point or another, a group of religious leaders who are opposed to the tribal government, and the majority of Hopis who are mostly uninvolved in politics but who follow the dispute quietly. Two of the two groups favor fighting for the land and relocating the Navajos in the Land given to the Hopis after the Joint Use Areas were divided into the Hopi Partition Lands and the Navajo Partition Lands by the government. The majority of Hopis agree in that those are Hopis Lands and that the Navajos should acknowledge that fact. Only the small group of traditional Hopis opposes relocating the Navajos in Hopi lands and allied themselves to radical Navajos (Benedek 1999, p. 26).

The Navajos are a very large tribe with a simpler social structure than the Hopis. They adopted sheep from the Spaniards and became semi-sedentary as a result. Navajos are "opportunistic" in that their value system does not condemn stealing or raiding. Their idea of the law is also very different from that of the Hopis in that "usage" of something is more important than "right" (Benedek 1999, p. 43). In other words, the Navajos believe that since they have been using that land and the Hopis have not, then they should have it. Since the Navajos lack a written history and a clearly defined 
religious hierarchy, their legends differ widely from person to person and differ greatly from those of the Hopi. The Navajos can be divided into three groups also: Navajos involved with the Tribal Council, the majority, and radical traditional Navajos. All three groups wanted to fight for the land but they differed in the means they were willing to use. The majority was relatively passive about the issue, the tribal council took a middle ground, and the traditional Navajos of Black Coal Mesa and Big Mountain took an extreme position (Benedek 1999, p. 372). While the Navajos worked together closely with white supporters they will be treated in a separate section since they are considered to be external players who influenced the main players, the Hopis and the Navajos.

\subsection{MAIN ISSUES IN THE LAND DISPUTE}

There were several main issues in the Navajo-Hopi Land Dispute. Taking a long term perspective, the most important issue for the Hopis was sovereignty. The Hopis wanted to have their view of history validated by the Navajos and by external observers. They wanted the world to accept that they had been in the land before the Navajos and that it belonged to them, at least de jure if not de facto. A second related issue was over Hopi identity and preservation of their culture. Due to the small size of the tribe there was a constant feeling of threat. The threat was that the tribe was going to be swallowed by the Navajos and that Hopis would just become a part of the large Navajo Nation. This means that identity was an important issue in the conflict. The Hopis were also concerned about the behavior of the Navajos. They wanted Navajos to be more "Hopi" or law abiding. The Navajo value system does not condemn stealing or raiding while the Hopi value system does. This value incompatibility was also an important issue in the conflict. It was a matter of whose law should reign in the land.

The Navajos also considered identity to be an important issue in the dispute. Traditional Navajos had an important religious and emotional connection to the land and their flocks. Removal from those lands threatened their identity and their culture. For the Navajos the main issue was usage of the land not so much ownership since that is a foreign concept for them. Survival was also an important issue for some Navajos since their lives depended on having enough land for their flocks and on being near a support network of relatives and friends that could help them in times of need.

Some individuals in both tribes had hidden agendas. Some Hopis involved in ranching would benefit greatly from the relocation of the Navajos and the exclusive use of the HPL (Hopi Partition Lands). Other Hopis were mainly concerned with their political careers and changed their positions accordingly. In the case of the Navajos, some were concerned with their political careers and others found meaning in their lives from the struggle. This is especially true for the radical youngsters who took an extreme position (Benedek 1999). Most were unemployed and the struggle gave them an opportunity to earn respect and to play an important role in tribal affairs. 


\subsection{TACTICS}

Both parties used a wide array of tactics. The tactics used range from legal action to violence. Hopis used: argumentation, legal action, passive resistance, press releases, lobbying, police harassment, refusal of building permits, and negotiation. The Navajos used: argumentation, legal action, press releases, lobbying, vandalism, civil disobedience, violence, and negotiation. Both parties launched propaganda campaigns to present their cases and to gain external allies.

The Navajos used tactics usually connected to movements of the left such as grassroots movements while the Hopis used more traditional tactics such as legal action and police enforcement of the law (Benedek 1999, p. 183). Finally, both parties used negotiation at several stages of the conflict and exchanged concessions.

\subsection{CHANGES IN THE CONFLICT AS IT DEVELOPED}

The conflict was originally handed in a case by case basis between the Hopis and the Navajos. Boundaries were negotiated by the individual Hopis and Navajos and most conflicts were managed in a peaceful manner. As the conflict went on and external players got involved the conflict became more legalistic and the parties polarized. The basic issues of the conflict related to sovereignty and identity were clouded by other factors such as control over mineral rights and petty legal details. Most importantly, the two main parties lost control over the direction of the conflict when powerful external parties entered the fray. The usual dispute between neighbors over stealing of fruits by a few Navajos was engulfed by the newly redefined conflict over legal ownership of the land.

The main change in the land dispute was the change of frame it underwent. A dispute between neighbors was reframed as a dispute over legal ownership which was then narrowed to issues of control over mineral rights and the land itself. The original issues of identity and culture were overshadowed by the framing imposed by external players such as the American government and lawyers.

\subsection{ENLARGEMENT OF THE CONFLICT}

As mentioned in the previous section, a dispute between neighbors over raiding and sovereignty over the land was enlarge to include many more players and issues. The two main original issues related to identity and culture were enlarged to include: control over mineral rights, fencing of the land, relocation, lifestyle, and self-determination. Tactics also moved from moderate argumentation to coercive tactics such as vandalism and violence. Both parties brought allies into the conflict and thus added to its complexity. Support groups, lawyers, politicians, bureaucrats, corporations, and activists 
got involved in the conflict. At some points the conflict even got average Americans involved in the conflict through opposition to the sell of public lands to the tribes.

\subsection{ROLES OF OTHER PARTIES}

Many external parties got involved in the conflict and in general they exacerbated the conflict by bringing in more resources and by introducing more issues. Lawyers for both sides, benefited from the legalistic framing of the conflict and from the continuation of it. In general, lawyers, even those representing the traditional Navajo families of Big Mountain, fostered the escalation of the conflict and the removal of some decisionmaking power from the hands of the affected parties (Benedek 1999, p. 318). In other words, they took over the conflict and led it in a legal direction and away from the cultural and identity issues. The American government exacerbated the conflict by imposing their form of government on the tribes and by drawing arbitrary boundaries between them. Thus, the Executive Order of President Chester A. Arthur, was the beginning of the legalization of the conflict (Benedek 1999, p. 35). Government agencies such as the Bureau of Indian Affairs (BIA) and the Navajo-Hopi Relocation Commission also disempowered the tribes by taking over decision making and implementation regarding possible solutions to the land dispute. Politicians further complicated the issues by supporting one position or another due to personal reasons and sometimes lacking the necessary information. Support groups such as BMLDOC (Big Mountain Legal Defense/Offense Committee) helped in the escalation of the conflict and promoted the polarization of both sides (Benedek 1999, p. 335). The alliance of the Navajo Tribe with labor unions, the IFL-CIO, further complicated matters by including political aspects and bringing in the antagonisms of those organizations (Benedek 1999, p. 198). Energy-related Companies also got involved it the conflict due to the mineral deposits in the lands disputed by the two tribes. Their involvement further aggravated the conflict by adding more issues to the original dispute and by bringing in the powerful influence and lobbying of energy interests (Benedek 1999, p. 138). Due to space constraints it is impossible to mention all of the external players involved in the Navajo-Hopi Land Dispute but they all took away decision making power away from the parties and helped escalate the conflict due to the resources they brought in and also due to the issues they included. It is also important to note that some mediation efforts were undertaken by bureaucrats and government officials such as the final one led by Judge McCue, that led to the 1995 Accommodation Agreement (Benedek 1999, p. 397).

\subsection{OUTCOME OF THE CONFLICT}

The final outcome of the conflict was that thousands of Navajos were relocated to the New Lands of the reservation and to neighboring towns. Millions were spent in legal fees and in the relocation. The core issues of the conflict were finally addressed during the negotiations that took place in 1992. Peterson Zah, President of the Navajo Nation, 
addressed the Hopi Tribal Council and accepted that the Hopis had sovereignty over the land and that all he wanted was for their help regarding his people living on the land (Benedek 1999, pp. 396-397). This simple gesture was immensely important for the Hopis. It validated their view of history and granted them the de jure ownership of the land that they had sought. After 18 months of negotiation with the help of a mediator, they reached a historic agreement that allowed the remaining people living in the disputed lands to sign a lease and to remain there (Benedek 1999, p. 392). Those people were also allowed to double their flocks and to practice their religion. Furthermore, the pending legal cases were also settled by giving the Hopis $\$ 50.2$ million to buy 500,000 acres in Arizona (Benedek 1999, p. 402). While the legal settlement is complex and involves permission to buy a certain number acres of land, the payment of money to the Hopis, legal fees, and other factors, the most important issues addressed by the 1995 Accommodation Agreement was that it permitted the people in the HPL to stay there as long as they signed a lease agreement for 75 years with the possibility of renewing it. The core of the agreement is the acceptance by the Navajos of the de jure sovereignty of the land by the Hopis and the acceptance of the Hopis of the de facto use of the land by the Navajos. Once that issue was settled, the Hopis were open to negotiate other matters such as the number of sheep and other animals that the Navajos would be allowed to have, the implementation of the law, fencing, and settling pending legal cases dealing with money matters. Finally, the families in the HPL were allowed to stay and to continue living in their traditional way. While the agreement reached with the remaining families in the HPL was satisfactory to both sides, the total outcome of the conflict was disastrous. Millions of dollars were spent on protracted legal battles, thousands of Navajo families were relocated to neighboring towns with no skills to survive there, family ties were strained or destroyed by the dislocation, and important support networks were disturbed or destroyed.

\subsection{DID ANY PARTY WIN?}

The Navajo-Hopi Land Dispute ended without either of the parties winning. Only the lawyers won through the millions of dollars in legal fees they made through the decades. Both parties spent a lot of money, time, and effort in the struggle that could have been used for more constructive ventures such as improving the lives of the people of both tribes (Benedek 1999). The outcome of the conflict simply confirmed what both parties had always known, that the land technically belongs to the Hopis but that the Navajos have historically used it. On a more particular level, the families that stayed in the HPL until the very end of the conflict won the right to remain there legally. Finally, both sides gained peace of mind by ending the conflict. 


\section{SOCIAL IDENTITY THEORY AND A CULTURAL APPROACH TO THE NAVAJO-HOPI DISPUTE}

Social Identity Theory provides a very good explanation for the Navajo-Hopi Dispute. This paper will follow Pieterse's model of ethnic domination as an example of social identity theory (Pieterse 2007, 2008). Pieterse's model of ethnic domination stresses the dialectic relationship between power and culture/identity (Pieterse 2007, p. 18). Interpreting the Navajo-Hopi Dispute through Social Identity Theory would emphasize the issue of cultural identity for the Hopis and for the Navajos (Augsburger 1992; Avruch 1998; Clark 1989; Dubinskas 1992; Faubion 2007; von Feigenblatt 2009; Pieterse 2007, 2008; Pruitt \& Kim 2004, p. 29). Both tribes asserted that the protection of their culture and their way of life was a very important issue behind the land dispute (Benedek 1999). For the Hopis the main concern was a fear of being absorbed into Navajo culture and that their culture would disappear (Benedek 1999, p. 149). This touches one of the group identity needs of the Hopis which is the protection of their distinct culture as separate from that of the Hopis (Pruitt \& Kim 2004, p. 30). The ability to practice their culture and religion was also connected to the land for the Hopis, in that they used it to collect eagle feathers and certain herbs. Thus, Social Identity Theory claims that the threat to those basic identity needs were at the core of the Navajo-Hopi Land Dispute. For the families living in the disputed land, identity needs were also very important. Their connection to the land is related to their lifestyle which in turn, is intricately connected to their religion and worldview. Thus, a removal from the land would threaten their most basic identity needs. Therefore, ownership of the land is only an issue in the conflict due to its connection to identity needs, not because of the intrinsic value of owning it.

The Hopis felt fraternalistic deprivation due to the fear of being absorbed by the more successful Navajo tribe (for a more detailed explanation of fraternalistic deprivation see Pruitt \& Kim 2004, p. 30). This led to the formation of quasi groups fighting for the disputed land. It is important to note that the fraternalistic deprivation that was felt by the Hopis was not due to any immediate physical need to use the land, but rather as a response to a collective threat of losing their separate identity and worldview. This is why it was so important for the Navajos to accept the Hopi claim of historical ownership of the land. The acceptance of Hopi de jure ownership instantly satisfied the Hopi identity need and thus the fraternalistic deprivation dissipated and many of the conditions necessary for conflict to take place were also removed (Pruitt \& Kim 2004, p. 33).

The same can be said of the Navajos. Once the Navajos were allowed to stay on the disputed land and continue with their traditional way of life, it was not so important whether they leased the land from the Hopis or from the Great Spirit. The identity needs of the Navajos were satisfied and thus their feelings of fraternalistic deprivation also dissipated. Secondary issues of the conflict were easily solved after the core identity issues were resolved. 
A cultural interpretation of the Navajo-Hopi dispute leads us to a very similar conclusion. According to this approach, cultural differences between the two tribes were at the core of the conflict. Differences in the importance ascribed to the law by both tribes and differences in the meaning of the land for both tribes were at the core of the conflict. For the Hopis the law is sacred and it must be followed and most importantly respected (Benedek 1999, p. 43). They have a view of law as an end in itself, while for the Navajos the laws are just a guideline to be negotiated on a daily basis. It is interesting how the views held by the two tribes regarding agreements and law mirrors the differences identified by Nisbett between Westeners and Asians (Nisbett 2003).According to his research, Westerners view agreements and the law as final while Asians view them as just a general guideline to be renegotiated when the need arises. Evidently this led to many problems in international negotiations between the two cultures and so did it play an important role in the Navajo-Hopi Dispute. This cultural difference explains why the Hopis placed so much emphasis on the Navajos accepting the law regarding their legal ownership of the land. For the Navajos the law was not as important as the fact that they were living on the land and that it was an integral part of their lives. Once the two apparently incompatible values were reconciled the other issues could be resolved. The Navajo-Hopi dispute fits this explanation in that once both sides agreed to respect the values of the other side, the other "realistic" issues were negotiated and resolved amicably.

\section{CONCLUSIONS}

The Navajo-Hopi Dispute is a complex conflict that can be traced to more than a hundred years ago. While the main conflict proliferated and produced many secondary sub-conflicts, this paper shows how identity and culture were at the root of the dispute and of its subsequent settlement. The macro-level of analysis adopted in this paper gives a better explanation of the overall conflict and filters out the noise introduced by secondary issues and external parties that were added along the way.

The first section of the paper identifies the main components of the conflict at the meta-level through the use of the simple instrument called SPITCEROW. Social Identity Theory was then used to analyze and interpret the main components of the meta-conflict. Finally, a broad cultural approach was used to support the explanation provided by Social Identity Theory. The paper concludes that culture and identity were at the core of the Navajo-Hopi Dispute and that once those issues were addressed the secondary issues were resolved amicably and the conditions supporting conflict behavior were removed. 


\section{LIMITATIONS}

The meta-level of analysis, space constraints, and the reliance on a single source of factual information about the Navajo-Hopi Land Dispute are important limitations of this paper. A choice had to be made between factual detail and the need to provide a relatively logical and parsimonious explanation of the overall conflict. Therefore, the conclusions presented in this paper should be treated as a tentative explanation of the very complex and protracted Navajo-Hopi Land dispute through an identity and cultural lens.

\section{REFERENCES}

- Augsburger DW 1992. Conflict Mediation Across Cultures: Pathways and Patterns First ed.. Louisville: Westmister/John Knox Press.

- Avruch K 1998. Culture \& Conflict Resolution. Washington, D.C.: United States Institute of Peace Press.

- Benedek E 1999. The Wind Won't Know Me: A History of the Navajo-Hopi Land Dispute Paperback ed.. New York: University of Oklahoma Press.

- Clark M 1989. The Cultural Spectrum. In Ariadne's Thread: The Search for New Modes of Thinking pp. 157-181. New York: St. Martin's Press.

- Dubinskas F A 1992. Culture and Conflict: The Cultural Roots of Discord. In D. M. Kolb \& J. M. Bartunel (Eds.), Hidden Conflict in Organizations: Uncovering Behind-the-Scenes Disputes pp. 187-208. London: Sage.

- Faubion JD 2007. Currents of Cultural Fieldwork. In P. Atkinson, A. Coffey, S. Delamont, J. Lofland \& L. Lofland (Eds.), Handbook of Ethnography Paperback ed., pp. 39-59. London: SAGE Publications.

- von Feigenblatt Otto F 2009. The Importance of Culture in Emic Interpretations of the History of Thailand's Southern Separatist Movement: The "Gentlemen's Agreement" of 1943 and the Relationship of Malaysia with the Separatists. Ritsumeikan Center for Asia Pacific Studies Working Paper, No. 09-7 October, 1-11.

- Gilles C (Cartographer). 1997. Hopis Tell Navajos: "Lease or Leave" 
- Hocker JL , Wilmot WW 2007. Interpersonal Conflict 7th ed.. New York: McGraw Hill.

- Nisbett R E 2003. The Geography of Thought: How Asians and Westerners Thing Differently... and Why 1st Paperback ed.. New York: Free Press.

- Pieterse JN 2007. Ethnicities and Global Multiculture: Pants for an Octopus Hardcover ed. Plymouth: Rowman \& LIttlefield Publishers, Inc.

- Pieterse JN 2008. Global Multiculture, Flexible Acculturation. In K. Archer, M. M. Bosman, M. M. Amen \& E. Schmidt (Eds.), Cultures of globalization : coherence, hybridity, contestation pp. 65-79. London: Routledge.

- Pruitt D , Kim SH 2004. Social Conflict: Escalation, Stalemate and Settlement (3rd ed.). New York: McGraw Hill. 